\title{
Middle Cerebral Artery Bifurcation Aneurysms Treated by Extrasaccular Flow Diverters: Midterm Angiographic Evolution and Clinical Outcome
}

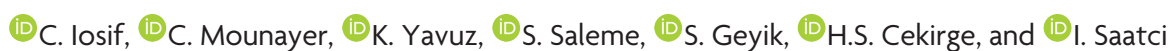

\begin{abstract}
BACKGROUND AND PURPOSE: Flow diverters have been increasingly used lately in off-label, distal intracranial aneurysm treatments. Our aim was to evaluate the effectiveness of flow diverters in the treatment of middle cerebral artery bifurcation aneurysms and to analyze midterm angiographic patterns of regional flow modifications for safety and clinical outcomes.
\end{abstract}

MATERIALS AND METHODS: Consecutive patients treated from January 2010 to December 2014 by the authors by using endovascular flow-diverting stents for MCA bifurcation aneurysms were evaluated retrospectively with prospectively maintained data. All patients had been followed for at least 12 months after treatment, with at least 2 control angiograms; regional flow-related angiographic modifications were registered by using a new angiographic outcome scale for flow diverters. Data were analyzed with emphasis on procedure-related events, angiographic results, and clinical outcome.

RESULTS: Fifty-eight patients were included in the study, with 63 MCA bifurcation aneurysms; 13 of these were large and giant. Pretreatment mRS was 0 for 12 patients (20.7\%), 1 for 41 (70.7\%), and 2 for 5 patients (8.6\%). Six-month control revealed mRS $0-2$ for 57 (98.3\%) patients and 3 for $1(1.7 \%)$ patient. Procedure-related morbidity and mortality were $8.6 \%(5 / 58)$ and $0 \%$, respectively. From $95 \%$ of still circulating immediate postprocedure angiographic outcomes, $68 \%$ progressed to aneurysm occlusion at 6 months and $95 \%$, to occlusion at 12 months, with a $0 \%$ aneurysm rupture rate.

CONCLUSIONS: Flow diverters seem to be an effective treatment alternative for complex MCA bifurcation aneurysms, with reasonable complication rates. Longer angiographic follow-ups are needed to assess the morphologic outcome; immediate subtotal occlusions do not seem to be related to rupture.

ABBREVIATION: FD = flow diverter

$\mathbf{F}$ ow-diverter (FD) stents have provided a paradigm shift in endovascular cerebral aneurysm treatment. Initially approved for carotid aneurysms, their use has been extended to include distal intracranial localizations such as MCA aneurysms. ${ }^{1}$ Covering intracranial arteries with FDs has recently been the subject of debate. While for localizations such as the posterior communicating artery, ${ }^{2}$ side branch coverage does not seem to have clinical

Received July 22, 2016; accepted after revision September 15.

From the Interventional Neuroradiology Department (C.I., C.M., S.S.), Dupuytren University Hospital (Centre Hospitalier Universitaire Limoges), Limoges, France; Interventional Neuroradiology Department (K.Y.), Ankara University, School of Medicine, Ankara, Turkey; Interventional Neuroradiology Department (S.G.), Memorial HealthCare Group, Istanbul, Turkey; Interventional Neuroradiology Department (I.S.), Yuksek Ihtisas University, Koru Hospital, Ankara, Turkey; and Interventional Neuroradiology Department (H.S.C.), Koru Hospital and Bayındır Hospital, Ankara, Turkey.

Please address correspondence to Christina losif, MD, MSc, PhD, 2 Ave Martin Luther King, 87042 Limoges, France; e-mail: christina.iosif@gmail.com, christinaiosif@yahoo.gr

- Indicates open access to non-subscribers at www.ajnr.org

http://dx.doi.org/10.3174/ajnr.A5022

consequences for patients, controversy exists regarding MCA branches.

The objectives of our study were to evaluate the clinical and midterm angiographic outcomes of FD stent placement for MCA bifurcation aneurysms with emphasis on the regional flow-induced modifications and their impact; the analysis was performed by using an angiographic classification ${ }^{3}$ that takes into account the hemodynamic evolution of the aneurysm and the regional anatomy with time.

\section{MATERIALS AND METHODS}

This clinical study included consecutive patients treated by multiple operators in several centers with endovascular flow-diverting stents for saccular MCA bifurcation aneurysms, ruptured and unruptured, during 5 consecutive years (January 2010 to December 2014). The prospectively maintained records of the patients were retrospectively evaluated by 2 , and in case of inconsistency, by 3 investigators independently. Initial data of 39 aneurysms were published in 2 previous studies. ${ }^{4,5}$ 


\section{Endovascular Technique and Procedure-Related Medication}

Therapeutic decisions were made by multidisciplinary consensus between interventional neuroradiologists and neurosurgeons. They were based on patient history, clinical presentation, and DSA; cases considered unfavorable for conventional endovascular treatment and failures or retreatment after previous endovascular or surgical procedures were selected. The patients' preferences were also taken into account, after having been informed of the risks of all potential alternatives. Written consent was always obtained before the intervention.

Antiaggregation protocols have been previously described. ${ }^{4,6}$ No patient was treated with $<40 \%$ platelet inhibition. Since January 2013, the protocol was modified by 2 operators (H.S.C., I.S.): Prasugrel replaced the dual antiplatelet regimen of clopidogrel and aspirin. All patients remained on dual antiaggregation or prasugrel for at least 6 months, continuing with aspirin monotherapy thereafter.

Therapeutic procedure details have been previously reported. ${ }^{5,7}$ For uncomplicated cases, single FD coverage and slight oversizing of 0.25 or $0.5 \mathrm{~mm}$ in diameter were favored, except for large and giant aneurysms. Systematic oversizing was done to decrease mesh density across the aneurysm neck, to obtain a slower progressive aneurysm occlusion with less risk of abrupt occlusion of the vessel coming off the sac. The presence of clips or stents was not a contraindication for the use of FDs in this study, but the treatment strategy and technical details remained at the discretion of the treating physicians.

\section{Clinical and Imaging Assessment}

Patients were clinically assessed with the modified Rankin Scale at each time point. Clinical statuses after treatment and eventual neurologic deficits at discharge or at follow-up were recorded. Any delayed clinical event, transient or permanent, was noted.

Immediate postdeployment DSA included DynaCT (Siemens, Erlangen, Germany) or VasoCT (Philips Healthcare, Best, the Netherlands) with diluted iodinated contrast medium, to assess stent apposition to the arterial wall, in addition to standard and working projections. At least 2 DSAs were performed at 6 and at least 12 months postintervention, including $2 \mathrm{D}$ and $3 \mathrm{D}$ selective angiographic runs. Results were evaluated according to the Cekirge-Saatci grading scale. ${ }^{3}$ Symptomatic narrowing or occlusion indicated occurrence of any transient or permanent symptoms attributed to compromise of the relevant branch; "reopening" indicated that a branch was enhanced better on a later DSA than in a previous study.

\section{Statistical Analysis}

The Fisher exact test was used for quantitative data after verifying normality by the De Agostino-Pearson test; the $\chi^{2}$ test was used for qualitative data. Statistical analyses were performed with appropriate software (Statistica; StatSoft, Tulsa, Oklahoma); the level of statistical significance was $P \leq .05$.

\section{RESULTS}

\section{Baseline Population Characteristics}

In the 5-year period, 58 consecutive patients ( 17 men, 41 women; mean age, $52.4 \pm 11.1$ years; range, $25-74$ years) with $63 \mathrm{MCA}$ bifurcation aneurysms were included in this study. Pretreatment
mRS was 0 for 12 patients (20.7\%), 1 for 41 (70.7\%), and 2 for 5 patients $(8.6 \%)$.

\section{Aneurysm Characteristics}

There were 10 large (15.9\%) and $3(4.8 \%)$ giant aneurysms, with the remainder being small. Thirty-eight of 63 aneurysms (60.3\%) were in the right MCA, and 39.7\%, in the left MCA. One aneurysm was treated on day 11 and another on day 1 post-aneurysm rupture (the latter aneurysm had been clipped 1 year before); 9 aneurysms were previously ruptured but were treated after the acute phase.

Fifty-two aneurysms had FDs as the first treatment, and 11, as the retreatment; among the latter group, 1 was a clipping failure and 10 were recurrences ( 1 previously clipped and 9 previously coiled aneurysms). Before FD treatment, 5/11 were classified as having a neck remnant (45.5\%), and 6/11, as having an aneurysm remnant (54.5\%), according to the Raymond-Roy classification. The first-treatment aneurysms had a mean aspect ratio of $1.6 \pm$ $0.7(65 \%, \leq 1.6$, and $34.6 \%, \leq 1.2)$ and a mean dome-to-neck ratio of $1.4 \pm 0.5(73 \%, \leq 1.5)$.

\section{Treatment and Technical Outcomes}

Fifty-seven aneurysms (90.5\%) were treated with the Pipeline Embolization Device (PED; Covidien, Irvine, California), 5 $(7.9 \%)$ were treated with the Flow-Redirection Endoluminal Device (FRED; MicroVention, Tustin, California), and 1 (1.6\%), with the Silk flow diverter (Balt Extrusion, Montmorency, France). Most of the aneurysms were treated with single FD coverage $(58 / 63,92.1 \%), 2$ were covered in a telescopic fashion $(3.2 \%)$, and there was adjunctive use of coils due to the large size for 3 aneurysms (4.8\%). In 3 other cases of single-FD coverage, the FD was deployed in a previously existing conventional intracranial stent.

Of the 63 aneurysms, 23 (36.5\%) were treated with prasugrel, and $40(63.5 \%)$, with double antiaggregation with clopidogrel and aspirin. Among the patients medicated with clopidogrel, 10 were rescheduled because of a low level of platelet inhibition and the need for increasing the drug dose and retesting.

Periprocedural complications were absent for 95.3\% (60/63) of the treatments, while periprocedural thrombus formation was encountered in $4.8 \%(3 / 63)$ of the cases; the latter was clinically evident as worsening of the clinical situation on awakening in 1 case and resulted in an increase of 2 points on the mRS score at discharge. The absence of peri- or postprocedure rupture (early or delayed) was ensured for all cases during the entire follow-up period.

\section{Clinical Outcomes}

Clinical mRS outcomes at discharge from the hospital were 0 for $12(20.7 \%)$ patients, 1 for $41(70.7 \%)$ patients, 2 for $3(5.2 \%)$ patients, and 2 for $2(3.4 \%)$ patients. During the postprocedure hospitalization, $6.9 \%$ of the patients $(4 / 58)$ developed procedurerelated ischemic events. One patient $(1.7 \%)$, with a giant aneurysm, developed a perianeurysmal brain inflammatory reaction in the fourth postprocedural week, which progressively resolved under steroids. One patient (1.7\%) developed ischemic stroke at 3 
Table 1: Modifications of the mRS throughout the follow-up period

\begin{tabular}{|c|c|c|c|c|c|c|c|c|c|c|c|c|}
\hline \multicolumn{2}{|r|}{ PRE tx } & \multicolumn{4}{|c|}{$\begin{array}{c}\text { Discharge mRS } \\
\quad(n=58)\end{array}$} & \multicolumn{4}{|c|}{$\begin{array}{c}\text { 6-Month mRS } \\
(n=58)\end{array}$} & \multicolumn{3}{|c|}{$\begin{array}{c}\geq 12-\text { Month mRS } \\
\quad(n=58)\end{array}$} \\
\hline $\mathrm{mRS}$ & No. of Patients & 0 & 1 & 2 & 3 & 0 & 1 & 2 & 3 & 0 & 1 & 2 \\
\hline 0 & 12 & 12 & 0 & 0 & 0 & 12 & 0 & 0 & 0 & 12 & 0 & 0 \\
\hline 1 & 41 & 0 & 37 & $1^{\mathrm{a}}$ & $2^{a}$ & 26 & 11 & $4^{\mathrm{a}}$ & $1^{\mathrm{a}}$ & 30 & 9 & 3 \\
\hline 2 & 5 & 0 & 4 & 1 & $1^{\mathrm{a}}$ & 3 & 1 & 0 & $0^{\mathrm{a}}$ & 3 & 1 & 0 \\
\hline Total & 58 & 12 & 41 & 2 & 3 & 41 & 12 & 4 & 1 & 45 & 10 & 3 \\
\hline
\end{tabular}

Note:-PRE tx indicates pretreatment values.

${ }^{a}$ Number of patients with clinical worsening in regard to pretreatment clinical status.

Table 2: Immediate postprocedure angiographic results and angiographic outcomes in controls

\begin{tabular}{lccc}
\hline $\begin{array}{c}\text { Cekirge-Saatci } \\
\text { Evaluation Scale }\end{array}$ & $\begin{array}{c}\text { Immediate } \\
\text { Angiographic Outcome }\end{array}$ & $\begin{array}{c}\text { I12-Month } \\
\text { Angiographic Outcome }\end{array}$ & $\begin{array}{c}\text { Third (Midterm) } \\
\text { Angiographic Outcome }\end{array}$ \\
\hline la & $3(4.8 \%)$ & $18(28.6 \%)$ & $16(40.0 \%)$ \\
lb & 0 & $14(22.2 \%)$ & $10(25.0 \%)$ \\
lc & 0 & $13(20.6 \%)$ & $8(20.0 \%)$ \\
2 & 0 & $2(3.2 \%)$ & 0 \\
3 & $1(1.6 \%)$ & $1(1.6 \%)$ & $1(2.5 \%)$ \\
$4 \mathrm{a}$ & $30(47.6 \%)$ & 0 & 0 \\
$4 \mathrm{~b}$ & $29(46 \%)$ & 0 & 0 \\
5 & 0 & $15(23.8 \%)$ & $5(12.5 \%)$ \\
Total & $63(100 \%)$ & $63(100 \%)$ & $40(100 \%)$ \\
& $\chi^{2}, 48.175 ; d f, 3$ & $\chi^{2}, 24.524 ; d f, 5$ & $\chi^{2}, 15.750 ; d f, 4$ \\
& Significance level, $P<.0001$ & Significance level, $P=.0002$ & Significance level, $P=.0034$ \\
\hline
\end{tabular}

months postintervention following discontinuation of clopidogrel without consulting the physician.

At 6-month control, mRS scores were 0 for 41 (70.7\%) patients, 1 for $12(20.7 \%)$ patients, 2 for $4(6.9 \%)$ patients, and 3 for $1(1.7 \%)$ patient. Clinical outcome at 6 months was good (mRS $0-2)$ in all except 1 patient $(98.3 \%)$. Clinical evaluation at the latest follow-up showed an mRS score of 0 for $45(77.6 \%)$ patients, 1 for $10(17.2 \%)$ patients, and 2 for $3(5.2 \%)$ patients. Modifications of the mRS throughout the follow-up period in regard to pretreatment status are shown in Table 1.

The permanent complication rate with poor prognosis $(\mathrm{mRS}>2)$ was $0 \%$. Procedure-related morbidity was $8.6 \%$ (5/58). Absence of aneurysm rupture and $0 \%$ procedure-related mortality were ensured for the population throughout the follow-up period. Among the patients who had ischemic events or transient symptoms, 4 were treated with clopidogrel and 1 , with a prasugrel regimen.

\section{Immediate Postprocedure Angiographic Results and Angiographic Outcomes}

Immediate postprocedure angiographic results and angiographic outcomes in controls are summarized in Table 2. Mean follow-up time for the entire group of patients was $22 \pm 9$ months (95\% CI of the mean, 19-24 months). Mean follow-up time for the third control was $28 \pm 9$ months (95\% CI of the mean, 19-60 months). Overall, all except 1 aneurysm (1/40, 2.5\%), controlled for $>2$ years postfollow-up, were either totally occluded or had stable remodeled regional angioarchitecture.

Statistical comparison of the 12-month with the 6-month DSA showed a statistically significant increase in the total occlusion rates for the 12-month controls $\left(\chi^{2}, 113.088 ; d f, 25\right.$; significance level, $P<.0001)$. The statistical comparison between the $12-$ month and the late midterm DSAs for the patients who had $>2$ angiographic follow-ups showed that all circulating aneurysms and $55.6 \%$ of the stable remodelling cases progressed to total occlusion $\left(\chi^{2}, 19.118\right.$; $d f$, 2; significance level, $\left.P=.0001\right)$.

From a $5 \%$ aneurysm occlusion rate on the immediate postprocedure angiograms, the series progressed to a $94.8 \%$ aneurysm occlusion rate at 12 months. None of the aneurysms in this series regressed from partial filling, stable remodelling, or total occlusion to aneurysm recirculation with time.

\section{Covered Branch Analysis and Hemodynamic Impact}

Angiographic outcomes regarding jailed branches are summarized in Table 3. The jailed branches were unchanged in 54\% of the cases at 6-month follow-up angiography, with stability in the further follow-ups up to $85 \%$. Symptomatic branch occlusion occurred in $2 / 63$ (3.2\%), both noted within first 6 months.

Three patients in the study had transient symptoms (DWI negative for ischemic events on MR imaging) attributed to hemodynamic factors during the first postprocedural months. These occurred on mean postprocedural day $33.6 \pm 8.6$ and resolved completely within 48 hours. One of the patients who developed postprocedure stroke at 24 hours postintervention showed sluggish flow on the final control angiogram at the end of the procedure.

\section{DISCUSSION}

MCA bifurcation aneurysm therapeutic strategy has been in dispute for the past few years. While clipping remains the mainstream treatment for these lesions, recent advances in the endovascular therapeutic approaches have involved several alternatives, including balloon remodelling, stent-assisted coiling, and, lately, the use of intra-/extrasaccular flow disrupters. Recent reviews failed to show a clear superiority of one approach over the other $^{8}$; nevertheless, surgery remains the mainstream approach for many cases. At the same time, complex cases, such as those with neighboring aneurysms ${ }^{9}$ and previous endovascular or sur- 
Table 3: Angiographic outcomes regarding jailed branches

\begin{tabular}{|c|c|c|c|c|c|c|}
\hline \multirow{2}{*}{$\begin{array}{c}\text { Jailed Branch Fate } \\
\text { Asymptomatic narrowing }\end{array}$} & \multicolumn{2}{|c|}{ 6-Month Follow-Up } & \multicolumn{2}{|c|}{ 12-Month Follow-Up } & \multicolumn{2}{|c|}{ 3rd (Midterm) Follow-Up } \\
\hline & 18 & $28.6 \%$ & 10 & $15.9 \%$ & 5 & $12.5 \%$ \\
\hline Symptomatic narrowing & 0 & 0 & 0 & 0 & 0 & 0 \\
\hline Asymptomatic occlusion & 9 & $14.3 \%$ & 0 & 0 & 1 & $2.5 \%$ \\
\hline Symptomatic occlusion & 2 & $3.2 \%$ & 0 & 0 & 0 & 0 \\
\hline Better opacification or "reopening" & 0 & 0 & 5 & $7.9 \%$ & 0 & 0 \\
\hline No change & 34 & $54.0 \%$ & 48 & $76.2 \%$ & 34 & $85.0 \%$ \\
\hline \multirow[t]{2}{*}{ Total } & 63 & $100.0 \%$ & 63 & $100 \%$ & 40 & $100 \%$ \\
\hline & \multicolumn{2}{|c|}{$\begin{array}{c}\chi^{2}, 36.365 ; d f, 3 \\
\text { Significance level, } P<.0001\end{array}$} & \multicolumn{2}{|c|}{$\begin{array}{c}\chi^{2}, 52.667 ; d f, 2 \\
\text { Significance level, } P<.0001\end{array}$} & \multicolumn{2}{|c|}{$\begin{array}{c}\chi^{2}, 48.650 ; d f, 2 \\
\text { Significance level, } P<.0001\end{array}$} \\
\hline
\end{tabular}

gical failures, ${ }^{10}$ emphasize the need for more alternatives in the neurovascular physician's therapeutic armamentarium.

FD treatments are increasingly being used for distal intracranial aneurysms. Some recent data even suggest better clinical outcomes with FDs than with stent-assisted coiling. ${ }^{11}$ A recent study by Caroff et $\mathrm{al}^{12}$ in 15 patients with MCA bifurcation aneurysms challenged previous studies with endovascular flow-diversion treatments in MCA locations, ${ }^{4,6,13}$ including large and fusiform aneurysms, ${ }^{14}$ by reporting a $43 \%$ ischemic complication rate.

In our study, apart from 1 perianeurysmal inflammatory reaction, reversible with steroid treatment, all other complications were ischemic but were limited to an acceptable rate $(8.6 \%)$. Three of 4 thrombotic ischemic events in the study occurred with patients treated with clopidogrel, and 1, with prasugrel. Even though all patients were systematically double-tested for resistance, lower thrombotic complications seemed to occur after switching to prasugrel.

Apart from 1 patient in whom clopidogrel was discontinued unauthorized at 3 months, the other 4 cases occurred in the early postprocedural period. In only 1 case was sluggish flow observed in an artery covered by a flow-diverter device in this study. We attribute such a low rate of sluggish flow to 2 main reasons: The first was because we systematically avoided device undersizing, actually preferring oversized FD deployment, resulting in decreased mesh density. The second reason could be the terminal nature of jailed branches. Recent laboratory data showed that terminal-type arteries, when jailed, tend to maintain poststenting flow rates similar to the prestenting ones in the acute poststenting phase; this scenario, in turn, seems related to decreased neointimal coverage of the jailed ostia at 3-month control. ${ }^{15-17}$

In accordance with previous reports, transient symptoms were noted during the first follow-up months. ${ }^{18}$ In our opinion, they were not related to in situ thrombotic events but rather to hemodynamic parameters. These events were not positively correlated with branch remodelling or occlusion; on the contrary, they were likely the expression of a regional decrease in perfusion, related to the presence of a moderately developed pial network, which might decrease the pressure gradient inside the jailed branch ${ }^{17}$ but was not yet sufficient to compensate for the perfusion requirement.

Progressive vasodilation and compensatory mechanisms were capable of resolving this matter as follows: Either the pial network was insufficient; thus, on follow-up, the jailed branch remained patent (Fig 1) or even became larger than that in previous controls; or the pial network would progressively augment, allowing at the same time, a progressive remodelling (ie, narrowing of the jailed branch; Fig 2). Overall in this study, early complications

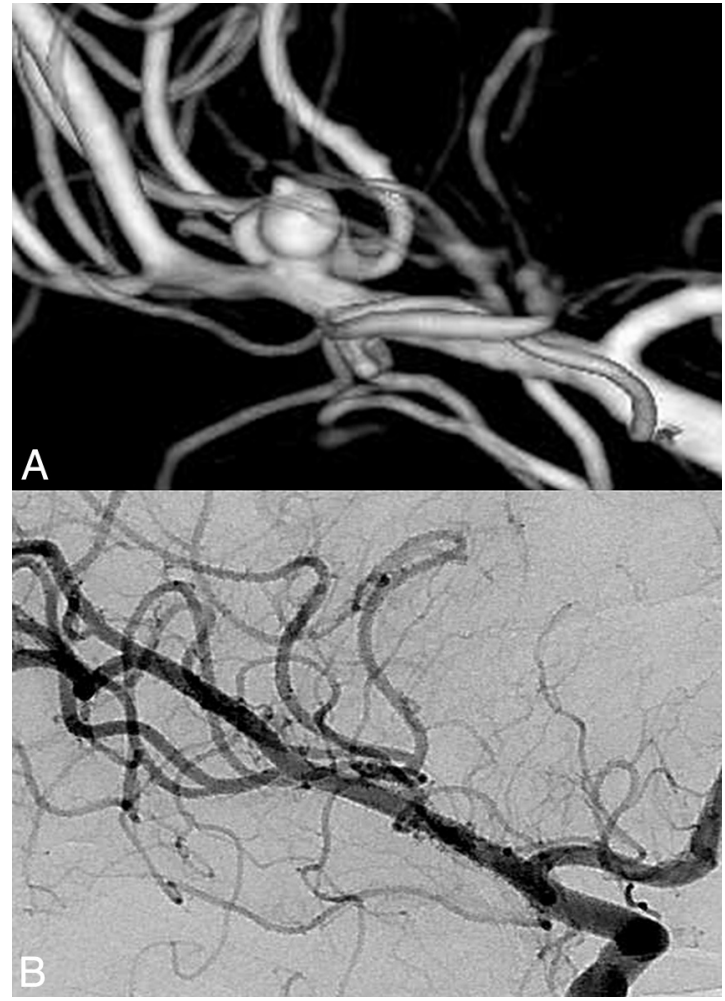

FIG 1. Pretreatment $3 D$ image $(A)$ shows a multilobulated right MCA aneurysm with a bleb. Note that the superior trunk originates from the sac. Control DSA 1 year after Pipeline Embolization Device placement. An image at a corresponding angle $(B)$ demonstrates total occlusion of the aneurysm with the branch coming off the patent sac (Cekirge-Saatci class la occlusion).

occurred mainly due to in situ thrombosis, probably related to undetected antiaggregation failures; late complications occurred due to either noncompliance with the antiaggregation regimen or hemodynamic effects. The latter resolved within hours and was not related to side branch occlusions.

Contrary to the recent published results from a clinical study on fusiform/dissecting MCA aneurysms, which positively associated total occlusion rates with side branch occlusion, ${ }^{19}$ our results did not show a correlation between side branch and saccular occlusion. On the contrary, an important percentage of the jailed branches remained patent. Furthermore, in cases in which the jailed branch showed transient symptoms during the initial postprocedural months, these branches tended to show unchanged caliber in the control angiographies.

Six-month angiographic controls in our study already showed important results in terms of aneurysm patency, but longer fol- 


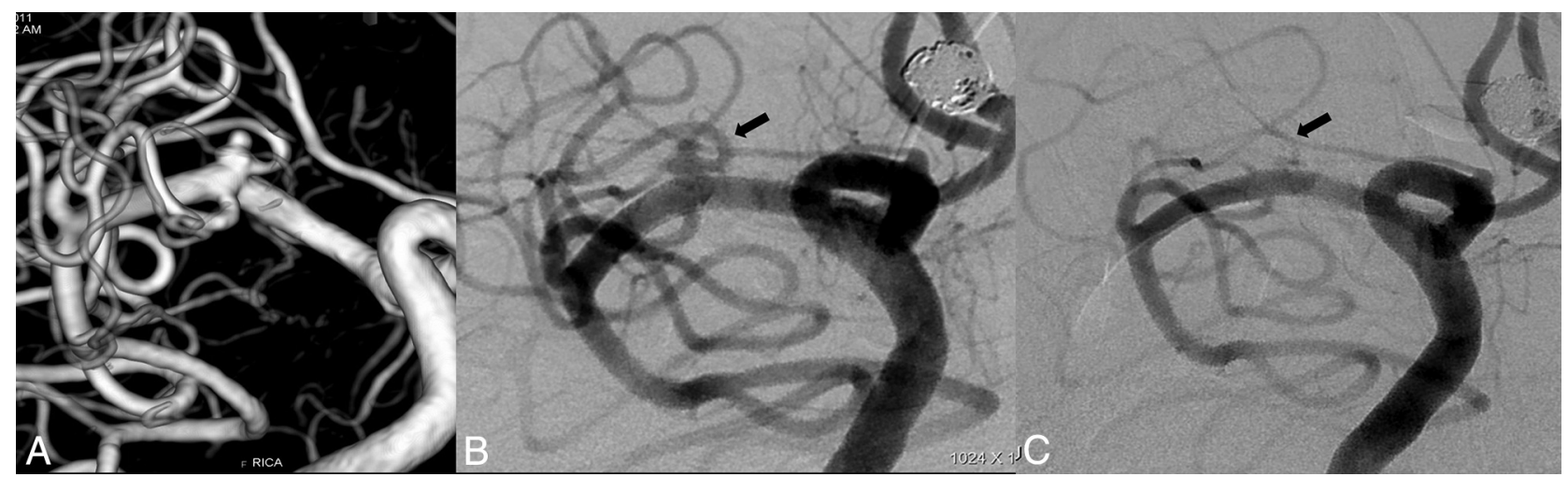

FIG 2. Pretreatment $3 D(A)$ and $2 D(B)$ images show a small, irregular right $M C A$ aneurysm with an early bifurcating branch (arrow) originating from the sac. Corresponding DSA obtained 1 year after PED treatment $(C)$ confirms the total occlusion of the aneurysm; the branch coming off the sac (arrow) is reduced in caliber (Cekirge-Saatci class lb occlusion).

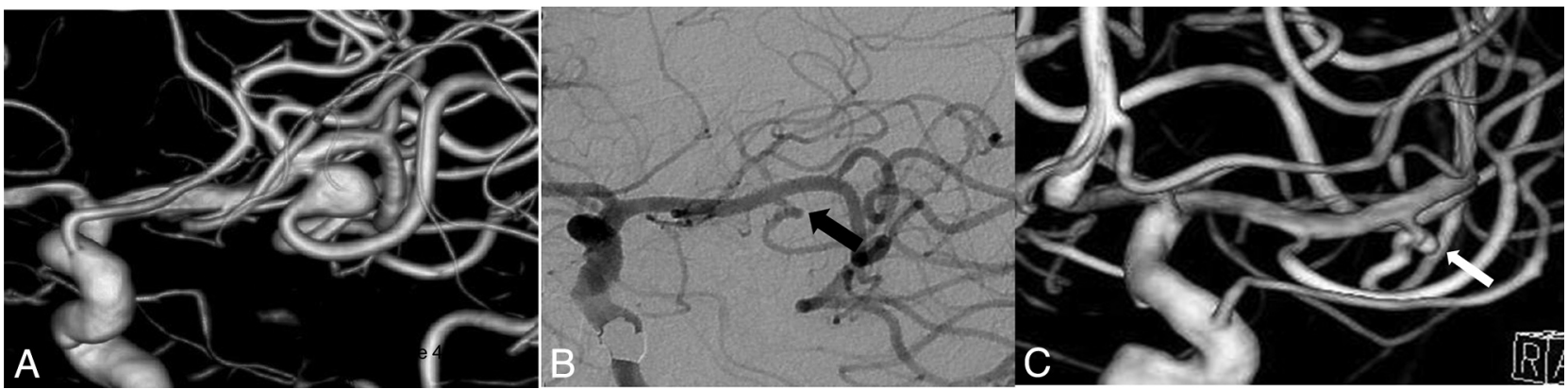

FIG 3. Pretreatment 3D image $(A)$ shows a left MCA aneurysm with the inferior trunk coming off the sac. Posttreatment 1- $(B)$ and 2-year $(C)$ angiograms confirm the stable occlusion of the sac with the patent inferior trunk (arrow) having a tortuous origin (Cekirge-Saatci class 5 occlusion).

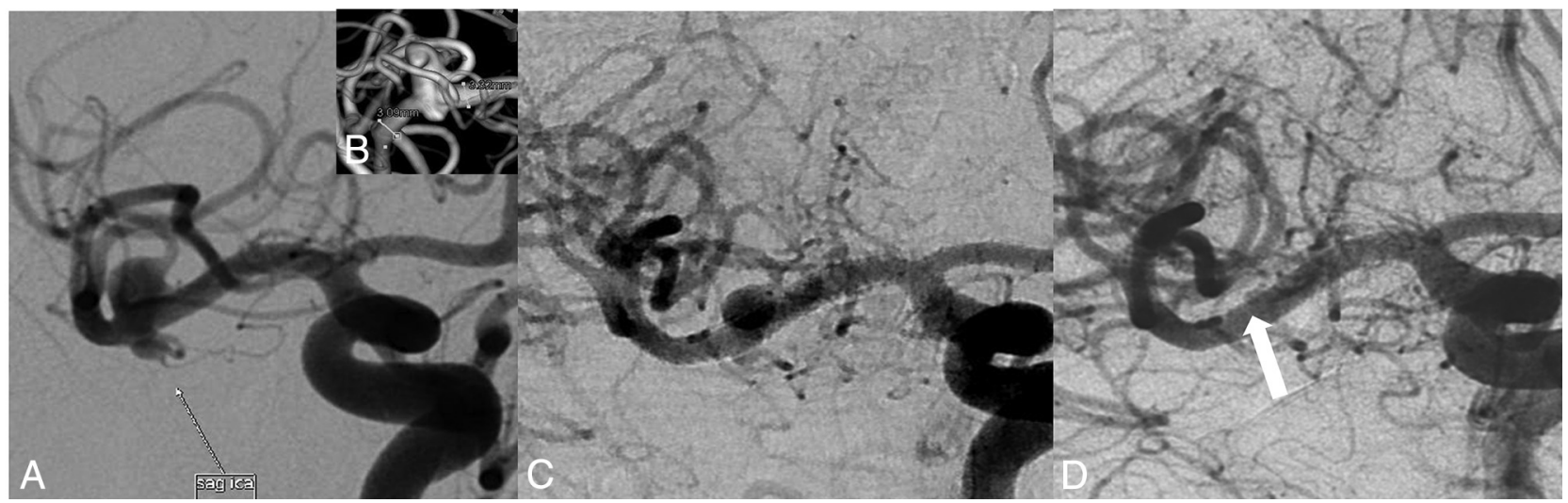

FIG 4. Pretreatment $2 D(A)$ and $3 D(B)$ images show an irregular right $M C A$ aneurysm with a bleb. Note that the aneurysm has no neck, and a branch is originating from the sac. Six-month control DSA image at a corresponding angle (C) reveals the sac decreased in size, but still filling (class 2). Correlative 1-year control DSA image demonstrates total occlusion of the aneurysm sac with the relevant branch filling retrogradely (white arrow) (ie, Cekirge-Saatci class lc occlusion).

low-ups revealed even further significant increases in total occlusion rates, as opposed to the study by Topcuoglu et al. ${ }^{19}$ In this study, $93 \%$ of immediate postprocedure circulating aneurysms progressed to $68 \%$ occlusion at 6 months and to $95 \%$ occlusion at 1 year. In this series, the rupture rate was $0 \%$ within the first year and beyond, similar to other recently published data. ${ }^{4,12,13}$

In this cohort of MCA bifurcation aneurysms, the flow-diversion effect, even though angiographically slow and progressive, still protected the aneurysms from rupture throughout the follow-up period (Fig 3). Angiographic assessment should probably be performed systematically later than the usual one (ie, 6 months) performed for other endovascular techniques (Fig 4). To our understanding, the Cekirge-Saatci angiographic evaluation scale seems more adapted for the evaluation of FD treatment, providing a more comprehensive evaluation not only of aneurysmal occlusion but of the whole hemodynamic modification process with time.

A recent study argued that the apparent shape of the covered branches and their disposition ${ }^{20}$ as to the aneurysm sac play an important role in both side branch patency and aneurysm occlu- 
sion. However, our observation is different in that these issues are more relevant to the terminal nature of the MCA bifurcation branches and the variability in pial anastomoses. The pressure gradient along a terminal artery is expected to persist after jailing, thus allowing the branch to remain patent. ${ }^{21}$ This feature may delay the process of aneurysm remodelling toward occlusion, but as found in the study presented herein, in the later followup, the aneurysms were occluded, with occlusion of the jailed branch not being a prerequisite.

In accordance with other reported cases, ${ }^{6,22}$ some patients exhibited an increased caliber of the jailed branch on later angiographic follow-up. These observations support the hypothesis that side branch remodelling after flow diversion is a hemodynamic process of constant re-adaptation, which can potentially evolve either way, not only toward progressive occlusion but also toward limiting endothelial coverage. ${ }^{15,17}$

Similar to our results, other recent publications have shown good clinical and anatomic results with flow diverters for MCA bifurcation aneurysms. Zanaty et $\mathrm{al}^{13}{ }^{13}$ in their series of complex large, giant, and bifurcation MCA aneurysms treated with the $\mathrm{PED}$, reported its effectiveness with reasonable complication rates.

Recent studies report promising results from intrasaccular flow-disrupting devices; nevertheless, initial complete occlusion rates were relatively low. ${ }^{23}$ Endosaccular flow disrupters have a specific shape and are made of nitinol filaments, which preserve their shape-memory properties; thus, they may not be adapted to every aneurysm anatomy or side branch configuration. Additionally, their hyperelastic properties along with the thrombus formation inside the device presumably play a role in the deformation described in the follow-up of some cases.

Even though surgical clipping has been considered a stable treatment of aneurysm recurrences, several studies have shown that this is not an absolute fact; clipped aneurysms may recur. ${ }^{24}$ Retreatment in these cases can be complicated for both the endovascular and surgical approaches. Adhesions from previous surgery, massive periprocedural bleeding, and anatomic complexity are issues to consider in microsurgical retreatment. ${ }^{24}$ Successful endovascular retreatments, though feasible, ${ }^{25,26}$ may be technically challenging for conventional techniques. Recent bibliographic data showed good outcomes with FDs in aneurysm recurrences after surgical clipping. ${ }^{25,27}$ In 2 series presented by Cekirge et $\mathrm{al}^{25}$ and Ding et $\mathrm{al}^{27} 2$ cases of clip failures and 3 cases of previous stent treatments were successfully retreated by FD embolization with very good results.

Large or giant, partially thrombosed aneurysms may be equally challenging for classic endovascular and microsurgical techniques; in this series, almost $21 \%$ of the cases were large/giant aneurysms. Flow diversion may not be the first-choice treatment for every MCA aneurysm, but complex cases may be successfully addressed, provided that some technical rules are respected, such as effective antiaggregation, careful sizing with slight oversizing, and meticulous control of stent apposition.

FDs are devices that appear to work in synergy with the dynamic vascular remodelling processes of brain; the technical strategy is to favor the regional remodelling to the patient's advantage. We are still a long way from completely understanding and ex- ploiting the full potential of these processes. Further research is needed, and until then, moderation in our conclusions would be more appropriate. FD use should be reserved for complex cases, and its results are to be evaluated with longer follow-ups. Nevertheless, taking extrasaccular flow diverters out of our therapeutic armamentarium for MCA bifurcation aneurysms seems just as imprudent as using them as first-line treatment.

\section{Limitations}

Even though the clinical and angiographic data bases for this cohort were maintained prospectively, the study design is retrospective; furthermore, the number of patients remains limited. Nevertheless, the conclusions of this study should be investigated with larger, multicenter studies.

\section{CONCLUSIONS}

Flow diverters seem to be an effective treatment alternative for complex MCA bifurcation aneurysms, with reasonable complication rates. An effective antiaggregation regimen is mandatory. Longer angiographic follow-ups are needed to assess the morphologic outcome; immediate subtotal occlusion was not related to rupture in the present study. The new angiographic scale seems adapted to the evaluation of the regional vascular remodelling post-FD stent placement.

Disclosures: H. Saruhan Cekirge_-UNRELATED: Consultancy: Medtronic, MicroVention, Sequent Medical. Isil Saatci—UNRELATED: Consultancy: Medtronic.

\section{REFERENCES}

1. Pistocchi S, Blanc R, Bartolini B, et al. Flow diverters at and beyond the level of the circle of Willis for the treatment of intracranial aneurysms. Stroke 2012;43:1032-38 CrossRef Medline

2. Brinjikji W, Lanzino G, Cloft HJ, et al. Patency of the posterior communicating artery after flow diversion treatment of internal carotid artery aneurysms. Clin Neurol Neurosurg 2014;120:84-88 CrossRef Medline

3. Cekirge HS, Saatci I. A new aneurysm occlusion classification after the impact of flow modification. AJNR Am J Neuroradiol 2016;37: 19-24 CrossRef Medline

4. Yavuz K, Geyik S, Saatci I, et al. Endovascular treatment of middle cerebral artery aneurysms with flow modification with the use of the Pipeline embolization device. AJNR Am J Neuroradiol 2014;35: 529-35 CrossRef Medline

5. Saleme S, Iosif C, Ponomarjova S, et al. Flow-diverting stents for intracranial bifurcation aneurysm treatment. Neurosurgery 2014; 75:623-31; quiz 631 CrossRef Medline

6. Iosif C, Camilleri Y, Saleme S, et al. Diffusion-weighted imagingdetected ischemic lesions associated with flow-diverting stents in intracranial aneurysms: safety, potential mechanisms, clinical outcome, and concerns. J Neurosurg 2015;122:627-36 CrossRef Medline

7. Saatci I, Yavuz K, Ozer C, et al. Treatment of intracranial aneurysms using the Pipeline flow-diverter embolization device: a single-center experience with long-term follow-up results. AJNR Am J Neuroradiol 2012;33:1436-46 CrossRef Medline

8. Santiago-Dieppa DR, Pannell JS, Khalessi AA. Endovascular and surgical options for ruptured middle cerebral artery aneurysms: review of the literature. Stroke Res Treat 2014;2014:315906 CrossRef Medline

9. Nussbaum ES, Defillo A. Surgical management and alternative strategies for neighboring intracranial aneurysms. J Neurosurg Sci 2012;56:345-48 Medline

10. Becske T, Kallmes DF, Saatci I, et al. Pipeline for uncoilable or failed 
aneurysms: results from a multicenter clinical trial. Radiology 2013; 267:858-68 CrossRef Medline

11. Zhang Y, Zhou Y, Yang P, et al. Comparison of the flow diverter and stent-assisted coiling in large and giant aneurysms: safety and efficacy based on a propensity score-matched analysis. Eur Radiol 2016; 26:2369-77 CrossRef Medline

12. Caroff J, Neki H, Mihalea C, et al. Flow-diverter stents for the treatment of saccular middle cerebral artery bifurcation aneurysms. AJNR Am J Neuroradiol 2016;37:279-84 CrossRef Medline

13. Zanaty M, Chalouhi N, Tjoumakaris SI, et al. Flow diversion for complex middle cerebral artery aneurysms. Neuroradiology 2014;56: 381-87 CrossRef Medline

14. Fischer S, Perez MA, Kurre W, et al. Pipeline embolization device for the treatment of intra- and extracranial fusiform and dissecting aneurysms: initial experience and long-term follow-up. Neurosurgery 2014;75:364-74; discussion 374 CrossRef Medline

15. Iosif C, Saleme S, Ponsonnard S, et al. Intravascular optical coherence tomography for the evaluation of arterial bifurcations covered by flow diverters. J Neurointerv Surg 2016 Jan 27. [Epub ahead of print] CrossRef Medline

16. Iosif C, Berg P, Ponsonnard S, et al. Role of terminal and anastomotic circulation in the patency of arteries jailed by flow-diverting stents: from hemodynamic changes to ostia surface modifications. J Neurosurg 2016:1-12 [Epub ahead of print] Medline

17. Iosif C, Berg P, Ponsonnard S, et al. Role of terminal and anastomotic circulation in the patency of arteries jailed by flow-diverting stents: animal flow model evaluation and preliminary results. J Neurosurg 2016;125:898-908 CrossRef Medline

18. Gawlitza M, Januel AC, Tall P, et al. Flow diversion treatment of complex bifurcation aneurysms beyond the circle of Willis: a single-center series with special emphasis on covered cortical branches and perforating arteries. J Neurointerv Surg 2016;8:481-87 CrossRef Medline
19. Topcuoglu OM, Akgul E, Daglioglu E, et al. Flow diversion in middle cerebral artery aneurysms: is it really an all-purpose treatment? World Neurosurg 2016;87:317-27 CrossRef Medline

20. Washington CW, Ju T, Zipfel GJ, et al. Middle cerebral artery bifurcation aneurysms: an anatomic classification scheme for planning optimal surgical strategies. Neurosurgery 2014;10(suppl 1):145-53; discussion 153-55 CrossRef Medline

21. Epilepsy: a clinical and experimental research-Proceedings of the Second European Regional Conference on Epilepsy, Warsaw, October 5-7, 1978. Monogr Neural Sci 1980;5:1-306 Medline

22. Berge J, Biondi A, Machi P, et al. Flow-diverter Silk stent for the treatment of intracranial aneurysms: 1-year follow-up in a multicenter study. AJNR Am J Neuroradiol 2012;33:1150-55 CrossRef Medline

23. Pierot L, Spelle L, Molyneux A, et al. Clinical and anatomical follow-up in patients with aneurysms treated with the WEB device: 1 -year follow-up report in the cumulated population of 2 prospective, multicenter series (WEBCAST and French Observatory). Neurosurgery 2016;78:133-41 CrossRef Medline

24. Spiotta AM, Hui F, Schuette A, et al. Patterns of aneurysm recurrence after microsurgical clip obliteration. Neurosurgery 2013;72: 65-69; discussion 69 CrossRef Medline

25. Cekirge HS, Islak C, Firat MM, et al. Endovascular coil embolization of residual or recurrent aneurysms after surgical clipping. Acta Radiol 2000;41:111-15 CrossRef Medline

26. Lubicz B, Leclerc X, Gauvrit JY, et al. Endovascular treatment of remnants of intracranial aneurysms following incomplete clipping. Neuroradiology 2004;46:318-22 CrossRef Medline

27. Ding D, Starke RM, Evans AJ, et al. Endovascular treatment of recurrent intracranial aneurysms following previous microsurgical clipping with the Pipeline Embolization Device. J Clin Neurosci 2014;21:1241-44 CrossRef Medline 